\title{
Warthin Tumor
}

National Cancer Institute

\section{Source}

National Cancer Institute. Warthin Tumor. NCI Thesaurus. Code C2854.

An adenoma characterized by an oncocytic, often papillary, epithelial component, dense lymphoid stroma, and cystic spaces. It occurs primarily in the parotid gland, and is the second most common benign parotid salivary gland tumor. A strong association with smoking has been reported. It typically presents as a painless swelling in the lower portion of the parotid gland. 